\title{
The Irish Post-Primary Education System - Critical Reflections of Teachers, Education Personnel and Early School Leavers
}

\author{
Seamus Morrissey \\ Galway City Partnership, Galway City, Ireland
}

\begin{abstract}
The issue of early school leaving is currently viewed as a particular concern in Galway City, Ireland. Despite national policy and numerous programmes, early school leaving continues to be prevalent. Through qualitative methodologies, primary data was collected from students, teachers, principals and education personnel. The student voice was viewed as a significant source of data within the study. Thirty-two semi-structured interviews were completed; sixteen of which were with early school leavers. These early school leavers, defined as having left the school system prior to completing the Leaving Certificate. Sixteen professionals, including teachers and principals, working with schools in Galway City were interviewed.

The study identifies disaffection and early school leaving as significant issues within the Irish education system. Disaffection, while complex, is identifiable among students through aggressive behaviour, disrupted attendance, poor relationships with teachers, lack of interest and non-engagement in academic processes. The research established that current policy aimed at tackling early school leaving is working on the periphery of schools rather than affecting change within schools.

The research also highlighted the existence of two original factors which are contributing to the issue of disaffection: 1) Tension among key constituents of the education system and 2) A 'culpability culture' among those who contribute to disaffection and the issue of early school leaving. Recommendations are outlined, including the need for a greater emphasis on inclusive policy and practice within the Irish education system.
\end{abstract}

\section{Introduction}

Early school leaving has been identified as a significant and ongoing issue within the Irish education system [1]. While national policy emphasises the need to remain in school until the age of 16 [2], the Economic and Social Research Institute (ESRI) defines early school leaving as 'leaving fulltime second-level education before completion of the Leaving Certificate' [3]. The Irish education system places such importance on the end point of a Leaving Certificate, consequently the ability of a system to include those students whose emphasis is not on completing the Leaving Certificate must be reflected upon. Furthermore, the education system purports, through national policy, to support inclusion but neglects to define what inclusion is or should be within education settings.

Galway City Partnership promotes social inclusion and aims to reduce social exclusion. Through my vocational experience, in particular within my current position as an Education Co-ordinator with Galway City Partnership in Galway City, the issue of students leaving school early has been identified as a significant concern in Galway City. This issue has been identified through different fora and among various agencies, services and institutions within Galway City. The primary focus of my current role is the promotion of social inclusion, with young people being a key target group. The rationale for this research has been developed in the context of promoting the inclusion of young people within society. Within this context, education is viewed as an extremely powerful tool in the promotion of inclusion and addressing poverty [4]; furthermore, as education of young people (hereafter referred to as 'students') constitutes an integral part of the development of inclusion in the city of Galway, this study will pay particular attention to that role.

\section{Research Rationale}

\subsection{Early School Leaving - Profile in Ireland}

The participation levels of students in post primary schools in Ireland trebled between 1960 and 1980 and the period since the 1980s has seen both an increase in participation and in the level of educational attainment [5]. In the most recent report 
by the ESRI, findings show that in $1980,40 \%$ of young people left school prior to the Leaving Certificate, however, by 1995 the number of early school leavers had dramatically decreased to $18 \%$. The percentage of early school leavers continued to decrease and by 2005 early school leaving was recorded at $14 \%$ which was a vast improvement from $40 \%$ in 1980 . The ESRI report confirmed that $86 \%$ of young people completed their Leaving Certificate in 2007; conversely, $14 \%$ of young people left the educational system prior to completion; this is a significant percentage when considered numerically as $14 \%$ represents almost nine thousand young people [6].

\subsection{Context for Early School Leaving Policy in Ireland}

"Early school-leaving, as a manifestation of educational disadvantage, has become a priority in national policy over the last 15 years" [7]. The prioritising of early school leaving in national policy manifests itself in the development of an extensive list of support programmes being implemented in post primary schools.

The focus of the Department of Education and Science on educational disadvantage has resulted in schools within disadvantaged areas receiving increased funding, resources and programmes. Consequently, the education system has developed a system of targeted supports to specific schools, primarily those operating within areas designated as 'Disadvantaged'. The potential, and emerging, consequence of such a policy is the further segregation and exclusion of those identified as both educationally and economically disadvantaged. From an inclusion perspective, the system of tackling educational disadvantage can be viewed as reinforcing disadvantage rather than addressing it. Through the development of a system of disadvantaged schools for disadvantaged students, a parallel system of non-disadvantaged schools for non-disadvantaged students develops [8]. Thus, an unequal and divided education system emerges.

The education policy of the Irish government is enacted through the development of different programmes and supports delivered locally in disadvantaged schools and, to a lesser extent, nondisadvantaged schools. The development of different programmes and supports has resulted in a fragmented system. In an attempt to address the fragmented nature of the programmes being implemented, the Department of Education and Science developed an Action Plan to merge all programmes. The action plan is titled DEIS
(Delivering Equality of Opportunity in Schools): An Action Plan for Educational Inclusion [9].

The aim of the DEIS action plan is to ensure the education needs of students from disadvantaged communities are prioritised and effectively addressed. A key function of DEIS is to place all the schemes and programmes, which have been operating in isolation, within one structure. The official documentation states that the action plan is "grounded in the belief that every student deserves an equal chance to access, participate in and benefit from education, each person should have the opportunity to reach her/his full educational potential for personal, social and economic reasons and education is a critical factor in promoting social inclusion and economic development" [10]. While DEIS refers to equality and social inclusion neither are defined or developed to any great extent. Therefore, the programmes outlined within DEIS are working towards equality and social inclusion in the absence of any clear vision of equality, social inclusion and inclusive education.

\section{Methodology}

Thirty-two semi-structured interviews in total were completed as part of the study. Sixteen of which were with early school leavers. These early school leavers, defined as having left the school system prior to completing the Leaving Certificate, were aged between fourteen and twenty-one. The interviews with students took place in community settings and training centres. Sixteen professionals, including teachers and principals, working with schools in Galway City were interviewed. The interviews took place in with teachers and professionals took place in schools.

\subsection{Students}

- Research gatekeepers are those who may give permission for research to proceed [11]. In this study, gatekeeping was viewed as contributing positively to the research through avoiding bias by the researcher in relation to the selection of the students and ensuring students disaffected from the second level education system were provided with an opportunity to participate in the research. Consequently, four services working directly with students at risk of leaving or who have already left the second level school system were written to informing them of the research, 
- The co-ordinator of each service was contacted by telephone,

- Each service agreed to participate in the research process,

- Through a formal meeting, each service was informed of the aims and objectives of the research. Furthermore, the co-ordinators of each service were informed of the ethical considerations,

- The co-ordinator of each service identified students who would be available for interview. It is important to note the number of males involved in these services is greater than females which reflects the gender breakdown within national statistics. Thus, this study has a greater number of males than females,

- The researcher contacted and got consent from parents of students under 18 (where relevant),

- Prior to each interview, the student (aged over 18) was informed of the content of the interview and was asked to sign a consent form,

- Each student signed a consent form and agreed to be interviewed,

- A time and location for interview was agreed and the interview was completed.

\subsection{Schools and Education Personnel}

- All second level schools in Galway City were written to in relation to the research,

- Each second level school was contacted by telephone,

- Three second level principals agreed to participate in the research and a teacher was recommended by a principal from a fourth school,

- One other school had agreed in principle to participate in the study but all attempts to formalise the process and arrange the interview were unsuccessful. The five other second level schools did not respond to the letter or phone call,

- Prior to each interview, the teacher or principal was informed of the content of the interview and was asked to sign a consent form,

- Each teacher or principal signed a consent form and agreed to be interviewed,

- A time and location for interview was agreed,

- Subsequently, principals and teachers recommended other teachers, ex-principals and a primary school principal to participate in the research,

- The recommended individuals were contacted,

- Prior to each interview, the recommended teachers and principals were informed of the content and each teacher or principal was asked to sign a consent form,

- $\quad$ Each recommended teacher or principal signed a consent form and agreed to be interviewed,

- A time and location for interview was agreed and the interview was completed.

The process of accessing and engaging the sample group, in particular the schools and education personnel, was extremely time-consuming and challenging. The topic of 'early school leaving' appeared to be viewed with suspicion and the study was treated similarly. In general there was a very limited response to written communication. Real engagement with the study was initiated through verbal communication. While this study included the views of four out of ten schools (one other school is not involved in the delivery of the Leaving Certificate curriculum and was not asked to participate in the study), five schools did not respond to any form of communication. One other school had agreed in principle to participate in the study but all attempts to formalise the process and arrange the interview were unsuccessful.

\section{Data Analysis}

Step 1 - Organising and preparing the data for analysis

Each interview was recorded and transferred from the voice recorder to computer. Each interview was given a label, e.g. Student 1 (subsequently, each student interview was given a pseudonym) or Education Personnel 1. Subsequently, each interview was transcribed and labelled as transcribed e.g. Student 1 (T). Finally, due to the style of language and dialect presented within the interviews, primarily by the students, each transcript was proofed for accuracy. Each interview was labelled as having being transcribed and proofed e.g. Student $1(\mathrm{~T} \& \mathrm{P})$

Step 2 - Read through all the data and begin detailed analysis with a coding process

The transcripts for this study were coded through two approaches: a) themes identified from a priori ideas [12] based on the research question and aims and objectives of the research and b) letting new codes emerge from the data set as the transcripts were being reviewed (Grounded Theory). In advance of outlining the coding process, an overview of Grounded Theory is provided. Grounded Theory is described as theory that was derived from data 
which was systematically gathered and analyzed. Within this framework the researcher begins with an area of study and allows the theory to emerge from the data [13].

Furthermore, Grounded Theory has procedures to help provide some "standardization and rigor" [14] to the process. Significantly, "these procedures were designed not to be followed dogmatically but rather to be used creatively and flexibly by researchers as they deem appropriate" [15].The purposes of coding, a key element of the procedure, are as follows:

- Build rather than test theory,

- Provide researchers with analytical tools for handling masses of raw materials,

- Help analysts to consider alternative means of phenomena,

- Be systematic and creative simultaneously,

- Identify, develop and relate the concepts that are building blocks of theory [16].

Operating within the context that Grounded Theory procedures "be used creatively and flexibly by researchers", it was decided that the themes would emerge through a priori coding and Grounded Theory coding. While the rationale for the study is steeped within the definitive existence of early school leaving and the vocational experiences of the researcher, the theory as to why early school leaving exists in Galway City has emerged from the data. Therefore, data gathered from students, teachers, principals and other education personnel in Galway City have provided the platform for the theory to emerge. This study operated within a constructivism paradigm [17].

\subsection{Coding Process}

The need, and purpose, of coding was particularly relevant in this study due to the large amount of 'raw material' gathered. Furthermore, a key aspect within my current role as an Education Co-ordinator is to work with schools but not within schools; the coding process provided the opportunity to identify and develop key concepts in relation to in-school policy and practice.

A set of a priori codes have emerged through the research questions and aims and objectives of the research. These codes are as follows:

1. Disaffection and Early School Leaving Evidence of disaffection and early school leaving,
2. Education Factors - Identifying factors which enhanced or inhibited the education experience for the sample group,

3. Disaffection Factors - Identifying factors which contributed to disaffection,

4. Deficit Discourse - The general discourse within the interviews relating to disaffection,

5. Policy Issues - Identifying issues which related to policy development and implementation.

The coding process was completed electronically through inserting codes through 'comments' in the text. Each transcript was read through and coded with a priori codes. Therefore, the codes were included on the right-hand side of each transcript. Furthermore, while reading through each transcript, any element of the data which was viewed as being 'of interest' to the research was noted through inserting a 'comment' in the text. Each transcript was then reviewed for a second time focusing on the elements identified as being 'of interest'. These elements of the data were noted and grouped together based on similarities across the transcripts. The following similarities were identified with the transcripts:

1. Tension - Tension between student and teachers/principals,

2. Blame - Mutual blame,

3. Socio-economic factors - Socio-economic factors,

4. Expectations - Teachers' expectations.

These four categories within the transcripts were developed into Grounded Theory codes: Tension, Blame, Socio-Economic Factors and Expectations. Each transcript was then recoded to include the above four codes. Therefore the transcripts were coded using the five a priori codes and the four Grounded Theory codes.

Once the coding process had been completed the analysis process was initiated. Data from each transcript which had been coded (under the nine codes) were then extracted and grouped under the nine codes. Initially, the transcripts from the students and teachers/principals/policy makers were grouped together. However, in order to ensure the student voice remained strong within the research, it was decided that the data from the students would be analysed and presented in one chapter and the data from the education personnel separately. As the data was being grouped, specific themes emerged. The themes which emerged are outlined in Table 1. 
Table 1. Themes emerging from Data Analysis

\begin{tabular}{|c|c|}
\hline The & $\begin{array}{r}\text { The Voice } \\
\text { Pers }\end{array}$ \\
\hline $\begin{array}{ll}\text { - } & \text { Views on Schools } \\
& \text { Reasons for Early } \\
\text { - } & \text { School Leaving } \\
& \text { Disafent } \\
\text { - } & \text { Absentecion } \\
\text { - } & \text { Schools and } \\
& \text { Inclusion } \\
\text { - } & \text { Teachers and } \\
& \text { Teaching } \\
\text { - } & \text { Deficit Discourse } \\
\text { - } & \text { Special Educational } \\
& \text { Needs and } \\
& \text { Curriculum }\end{array}$ & \begin{tabular}{|ll} 
- & School Culture and \\
& System \\
- & Inclusive/Exclusive \\
& Schools \\
- & Deficit Discourse \\
- & Teachers and \\
& Teaching \\
- & Student \\
& Disaffection from \\
& Others' \\
& Perspectives \\
- & National Policy \\
- & Student Profile and \\
& Background \\
- & Culpability Culture
\end{tabular} \\
\hline
\end{tabular}

\section{Findings}

Three of the themes identified through the data analysis will be focused on in this paper: Disaffection (Student and Others perspective), National Policy and Culpability Culture.

\subsection{Disaffection (Student and Others perspective)}

\section{Table 2. Depiction of Disaffection}

"I was very bad, throwing things at the teachers, hitting the teachers, telling them to f..k off ... Standing up on top of the tables was one thing anyway, singing." (Michael)

"I don't know I got sick of the school. I got sick of going in. I got sick of it and left ... I was arrested a few times. That was during school." (Kevin)

"I don't think the teachers like people from Westside for a long time anyway. Because there is other people that went to school there and they all got kicked out too and quit before [sic], so it was kind of habit for us." (Thomas)

"I don't know, it just made me feel normal. Just being a bit of a scumbag because they think we are scumbags.” (Philip)

"[Disaffection] being late for class and then when they are pulled up on things, responding very badly and you know maybe shouting and roaring and being very disrespectful to teachers, abusive to teachers." (Education Personnel 1)

"I have seen disaffection. Well it presents itself in terms of a kind of unwillingness to engage with the curriculum, unwillingness to engage with teachers, unwillingness very often to engage with the other students and generally be unhappy and just not prepared to do anything." (Education Personnel 3)

"They're bored, they're lacking motivation, they don't want to do it where as typically if they're doing something they enjoy and something that stimulates them and they have a fair bit of input into it." (Teacher 3)

Table 2 provides an insight into the experiences of young people within the education system. The reasons for disengagement from the system must be viewed in the context of an education system which is failing to meet the educational and social needs of all students. The students involved in the study have emerged from second level schools frustrated, angry and disillusioned with the system. The students recollect examples of disaffection, absenteeism and challenging behaviour while involved in second level education. Further analysis indicates a culture clash exists between the perspective of the student and that of teachers and principals involved in delivering education. Such a clash creates a tension which impacts on the students' participation within the education system.

The experiences of teachers and principals through day-to-day contacts with students further emphasises the issue with disaffection. Issues in relation to teacher-student relationships were identified as impacting on students' participation in the education system. Furthermore, the limited impact of policy addressing early school leaving is identified through the accounts of teachers and principals. The culture and language in existence in schools are impacting negatively on the level of inclusion within the education system. 


\subsection{Implications of National Policy}

\section{Table 3. Implication of Policy}

"I think what we've done is create a monster called the Leaving Cert. Parents think it's the Holy Grail ... Their kids will get the points and get into college; they think they've arrived." (Principal 3)

"Galway City is a very interesting place to do this study ... You have apartheid of education here. And it's not said, but it's done ...Y You have the instance there is a polarization of people, that school is for them and this school is for us ... The inclusivity of some schools works to the benefit of the exclusivity of everybody else" (Principal 1)

"DEIS offered economic assistance to schools, who were trying to support students at risk, that while it was positive at that level, that it just compounded the whole theme of apartheid within the school level education system." (Teacher 1)

Table 3 introduces a level of tension among second level education providers and implementers in Galway City. The tension emerges due to the implementation of national policy through local programmes. Government policy focuses on the delivery of supports through a system of designating schools as disadvantaged. The evidence indicates that "while DEIS offered economic assistance to schools, who were trying to support students at risk ... it just compounded the whole theme of apartheid within the school level education system" (Teacher 1). This suggests that such a policy has extremely negative effects on second level education in Galway City. Government policy, such as DEIS, has developed a segregated system of disadvantaged and non-disadvantaged schools. National policy has developed a system, as one teacher described it, with a "theme of apartheid within the school level education system" (Teacher 1). Within the context of national policy, schools which are designated as disadvantaged have attracted students with specific educational needs or at risk of disaffection.

Furthermore, students at risk of early school leaving are being pushed by non-disadvantaged schools towards the resources being provided in the disadvantaged schools. Conversely, the 'most academic' students are moving towards the non- disadvantaged schools in Galway City. A second level education system which supports such segregation within schools is, consciously or unconsciously, supporting segregation and separation within society. The evidence supports the suggestion that the second level school system in Galway City is creating a system of exclusion. As a result there will be significant long-term effects on Galway City. For as long as the profile within schools is different to the profile of society the promotion of an inclusive and equal society in Galway City will be extremely challenging. Furthermore, in the context of the limitations of national structures to create and promote change in the community, the impetus for change lies with the community organisations, parents and students themselves.

\subsection{Culpability Culture}

Table 4. Culpability Culture

"I would be very unhappy with the system at the moment. But I think that what should be challenged is every school in the country. Every school should be challenged on the same take." (Principal 1)

"The system doesn't suit them. We haven't looked at young people and said look it, these people are suited to being active out doing work but at the same time out being trained."

(Principal 3)

"[Retention] depends on the home background to a great extent." (Principal 2)

"I've seen that in my school and I see it from parents who are not interested either and half the problem, most of the problem, is the parents." (Principal 3)

Table 4 and data gathered within the study provides evidence that there is a 'blame culture' within schools. This culture is emphasised through blame being placed on various factors such as the background of the students, including the role of parents and the education system. The 'culpability culture' is not just restricted to school staff. There is mutual culpability. Throughout the interviews with the students, there is evidence of blame being placed on teachers and school management for their disaffection from the education system. The 
'culpability culture' must be viewed as contributing to the complexity of the issue of disaffection. Such culpability detracts from the implementation of policy and examination of issues within the education system i.e. disaffection and early school leaving. Furthermore, the existence of such culpability contributes to tension among the key constituents within the education system. Culpability is a derivative of a lack of understanding and trust among key parties of education in Ireland. In the absence of understanding and trust, tension manifested through blame emerges. Figure 1 illustrates the process of the development of culpability.

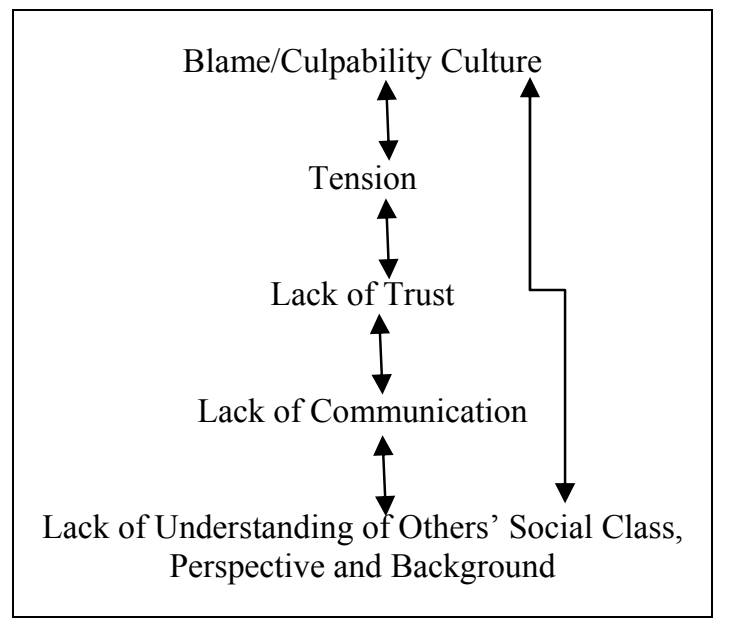

\section{Figure 1. Model of Culpability Development Process}

Figure 1 outlines the culpability development process within the Irish education system. Lack of understanding of other social classes, perspectives and background, especially among teachers, contributes significantly to culpability. Due to lack of understanding and lack of perceived common ground, communication can become limited or nonexistent. In the absence of communication, the development of trust is limited and consequently feeds mistrust. Based on lack of understanding, communication and trust, tension and blame will emerge. The cyclical nature of this process is important as culpability will continue to exist until the four elements are addressed and overcome.

The existence of blame among school staff can be viewed as a 'mechanism of separation' from the issue of students leaving school early. Placing blame onto individuals, groups or society can be viewed as a removal of oneself from the cause and resolution of the problem. Furthermore, blame can suggest a lack of interest in resolving the issue at hand. On the contrary, such separation can be explained as an indication of a skills deficit or lack of ability to resolve the issue. As identified by the NASUWT [18], teachers are trained and placed in positions to teach students and are not provided with the professional skills or training to work with families and local communities. The evidence suggests the need for such support, yet it is viewed as outside the brief of schools. As mentioned previously in this study, the need for inter-agency co-operation is required. Such co-operation requires a commonality of interest; in this case the common interest can be the student voice. The sustained existence of blame, as well as the absence of communication and cooperation among parties to the education system, will continue to facilitate a system which is failing to meet the needs of students.

\section{Discussion}

\subsection{Disaffection and Early School Leaving}

Disaffection and early school leaving are significant issues within the Irish education system. Disaffection, while complex in its structure, is identifiable among students through characteristics such as aggressive behaviour, disrupted attendance, poor relationships with teachers, lack of interest and non-engagement in academic processes. The presentation of such characteristics by students must be viewed as a definitive move towards leaving the school system in advance of completing the Leaving Certificate. Through the research process, a model of the Complexity of Disaffection has emerged. While acknowledging the existence of external factors such as social and economic issues, the model highlights the influence education policy, schools and students have in relation to disaffection. Through the critical analysis of policy and data analysis the following four key areas were identified as contributing to disaffection: Education Policy, Students, School and 'Culpability Culture':

1. Education Policy - Contributing Factors: government education policy; 'intention-reality' gap; lack of formal evaluation of programmes implementing government policy; insufficient resources; complexity of structures within the education system; fragmented structure within the education system; lack of clarity on inclusive education and web of policies.

2. Student Contributing Factors: low expectations of self; socio-economic background of student; diverse education needs; specific education needs; personal and social needs; educational disadvantage and parental expectations.

3. School Contributing Factors: teacher expectations; teaching methods; placing blame 
on external factors such as student background; culture and value system within school; lack of understanding of inclusive practice; profile of students within school; allocation of teachers within school; streaming of students and type of second level school.

4. Culpability Culture: The issue of disaffection is further complicated by blame. Each constituent to disaffection places blame on another. The apportioning of blame blurs the ability to identify the 'finite' causes of the disaffection.

The model outlines how the four key areas contribute to student disaffection. With the focus of this research weighing heavily on the student voice, the research clearly indicates that schools, in particular teachers, are key contributors to disaffection and to students leaving the education system early. The students are vociferous in their condemnation of their experiences of the Irish education system. The student voice describes a second level education system which has failed to meet their educational needs. They feel alienated and devalued by a system which perpetuates the middle class values of the teachers and management and takes little account of their culture and socioeconomic groupings. Their views depict a second level education system which deliberately excludes students perceived as being outside of the 'norm'.

Furthermore, this research provides definite evidence of an education system which has neglected to develop and implement policy which would proactively create inclusion within educational practice in second level schools in Galway City. Within an Irish context, policy and programmes have been implemented to reverse the 'move' towards leaving school early but the impact of policy and programmes has been extremely limited. The limitations of policy can be attributed to the focus on changing the individual rather than tackling the system which is facilitating and encouraging the movement of students towards leaving school early.

\subsection{Tension within the Education System}

Significantly, through this study a contentious issue has emerged which is entrenched in the education system. Tension among, and between, key constituents of the education system emerged as impacting on the ability of the education system to operate in a cohesive manner. Furthermore, such tension is impacting on the ability of national or local policy to effect change within the education system. Tension exists throughout the education system with evidence of three key 'settings' of tension. Figure 2 identifies three setting of tension:
1) Teacher and Principal - Department of Education and Science, 2) Disadvantaged Schools - NonDisadvantaged Schools and 3) Student - School Staff (Teacher and Principal):

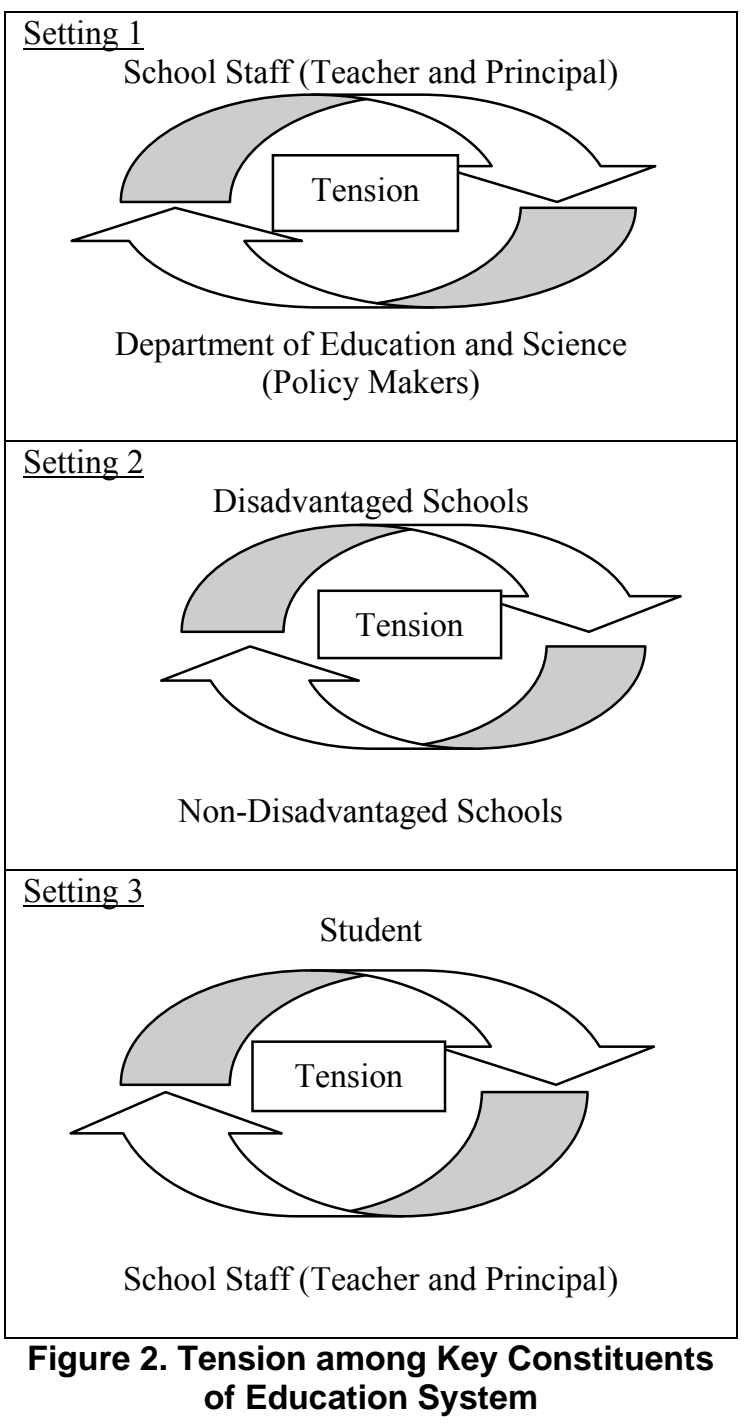

Through the analysis of data, in particular the codes and themes which emerged through the grounded codes, a theory emerged that tension between constituents of the education system is a key contributory factor to disaffection and early school leaving among students. This tension has created a 'vicious circle' environment in which there is an ongoing 'power-control' struggle between the constituents within the education system. In each case, both constituents have the power to impact on the other's experience of the education system. The effectiveness of policy is limited due to the ongoing 'power-control' struggle, a struggle which will 
impact on the development of inclusive education practices.

Setting 1 refers to tension between School Staff and the Department of Education and Science (Policy Makers). The Department of Education and Science has 'power-control' in relation to funding of teaching hours and staff, resources or supports (special educational needs supports and materials), development of curriculum, development of national policy and overall responsibility for the future of education. School Staff (and management) retains 'power-control' in relation to the implementation of policy, the culture of the school, streaming of students, allocation of teachers and resources within the school, discipline process and inclusion/exclusion of students. Both constituents are attempting to retain or impose a level of 'powercontrol' over the other. Furthermore, the hierarchical nature of the system must be viewed as a contributing factor to the tension within this setting.

Setting 2 refers to tension between disadvantaged schools and non-disadvantaged schools. In this situation, non-disadvantaged schools are in a position of 'power-control' to include and exclude students from the school. Non-disadvantaged schools are in a position to attract and select students with low risk of disaffection. Conversely, disadvantaged schools are limited in their ability to include and exclude students. However, disadvantaged schools are provided with a greater level of state funding than non-disadvantaged schools. Disadvantaged schools have power, control and resources to provide increased levels of support to students at risk of disaffection through training and resources from the Department of Education and Science. Both constituents are attempting to retain or impose a level of 'power-control' over the other. To further illustrate the existence of such tension, and the contributions this study will make to the body of knowledge, in July 2009 a Vocational Education Committee on behalf of a disadvantaged school took a case to a high court in Ireland. A student expelled from a non-disadvantaged school was being 'offloaded' to a disadvantaged school. The Department of Education and Science ruled the disadvantaged school must take the student. However, Mr. Justice Daniel O'Keeffe found that the Department of Education and Science's appeals committee did not have the right to compel a school to take on a difficult or disruptive student expelled by another school [19]. The long-term effects of this ruling are unclear. However, the findings of this research illustrate similar tension and concerns exist in Galway City between disadvantaged schools and non-disadvantaged schools.
Setting 3 relates to tension between the student and the teacher/principal. Teachers and principals have 'power-control' in relation to influencing the culture of the school, streaming of students, allocation of teachers, discipline process, suspension and exclusion of students. Each of these factors can, individually and collectively, have a fundamental impact on the educational experience of the student. Conversely, students have 'power-control' in relation to attending school, engaging with teachers, engaging with the discipline process of school, influencing the culture of the school and participating in the assessment process. Both constituents are attempting to retain or impose a level of 'power-control' over the other. Furthermore, tension is perpetuated due to the differing values and cultural backgrounds between students and teachers/principals.

The existence of such tension throughout the education system directly, and indirectly, impacts on the development and implementation of policy, delivery of curriculum, support for students, support for teachers, access to resources and ultimately the extent of 'inclusion' within the education system. From the viewpoint of this study, the effectiveness of national policy is negatively impacted upon by the tension which exists within the Irish education system. The long-term effectiveness of any education related policy will be dependent on the 'release of tension' from the system. Central to this release will be the reduction of the 'level of division' between the Department of Education and Science and schools. The 'ownership' of schools is central to this issue but the need for a collaborative approach is evident. School management and the Department of Education and Science must create a system of formal collaboration which facilitates both parties' involvement in policy development and implementation, rather than the current system in which the Department of Education and Science develops policy and schools implement policy.

\section{Conclusion}

This study established that disaffection and early school leaving continue to exist due to factors relating to current education policy (development and implementation), students, schools and a 'culpability culture' within the education system. Furthermore, the problem of disaffection and early school leaving is fuelled by intricate tension which exists within the education system. Feasible solutions for tackling disaffection and early school leaving have been developed including the need to move towards an inclusive education system through 
the development of a multi-agency approach in which there is a shift away from a 'culpability culture' to a common agenda. Moreover, student needs must be placed at the centre of the education system, a system which needs to move away from tackling educational disadvantage to promoting inclusion of all students within the education system.

Through the data analysis the study demonstrates that disaffection and early school leaving are significant issues within the Irish education system. Disaffection as outlined within the data analysis, while complex in its structure, is identifiable among students through characteristics such as aggressive behaviour, disrupted attendance, poor relationships with teachers, lack of interest and non-engagement in academic processes.

The research also established the existence of two original factors which are contributing to the issue of disaffection. The first is tension within the education system. The following contribute to such tension: clash of cultures and 'power-control' struggle among teachers and students; 'power-control' struggle between disadvantaged schools and nondisadvantaged schools; 'power-control' struggle between schools and the Department of Education and Science; and a propensity within policy towards addressing educational disadvantage rather than promoting inclusive education. The second factor is a 'culpability culture' among those who contribute to disaffection and the issue of early school leaving. Education policy makers, students and schools have created a culture of culpability, a culture in which each places blame on another for the issue of disaffection.

\section{References}

[1] Government of Ireland, (2007), National Action Plan for Social Inclusion 2007-2016, Dublin, Government Publication.

[2] Government of Ireland, (2000), Education (Welfare) Act 2000, Dublin, Government Publication.

$[3,6]$ Byrne, D. \& Smyth, E., (2010), "No Way Back? The Dynamics of Early School Leaving". Dublin: The Liffey Press.

[4] Barry, U., 2010, "Life-Long Learning and New Skills in Ireland: A gender Perspective". UCD School of Social Justice Working Papers Series. 10 (2), pp. 1-27. Dublin: University College Dublin.

[5] McCoy, S., Kelly, E. and Watson, D., (2007), School Leavers' Survey Report 2006, Dublin, Economic and Social Research Institute (ESRI) and Department of Education and Science.
[7] Fleming, T. and Murphy, M., (2000), Squaring the Circle An Analysis of programmes in Dublin schools to prevent early school leaving. With recommendations for effective best practice, pp 8-10, Dublin Employment Pact, Policy Paper No 3.

[8] Lynch, K., (1989), The Hidden Curriculum Reproduction in education, an appraisal, London, The Falmer Press.

[9, 10] Department of Education and Science, (2005), DEIS (Delivering Equality of Opportunity in Schools), pp14-15, Dublin, Government Publication.

[11] Homan, R., (2002), 'The principle of assumed consent: The ethics of gatekeeping', in M. McNamee and D. Bridges (eds.) (2002) The Ethics of Educational Research, Oxford, Blackwell Publishing.

[12] Saldaňa, J. (2009) The Coding Manual for Qualitative Researchers, Los Angeles, Sage Publications.

[13, 14, 15, 16, 17] Strauss, A., and Corbin, J., (1998), Basics of qualitative research: Techniques and procedures for developing grounded theory (2nd ed.), pp12-14, Thousand Oaks, CA: Sage.

[18] National Association of Schoolmasters Union of Women Teachers, (2008), NASUWT Annual Conference Resolutions of the Annual Conference held in the ICC, Birmingham, March 2008, accessed through www.nasuwt.org.uk ( $25^{\text {th }}$ of June, 2009).

[19] Hughes, P., (2009), 'VEC chief hails landmark High Court ruling', Irish Independent, Tuesday, 14th July, 2009, accessed through www.ireland.ie $\left(15^{\text {th }}\right.$ of July, 2009). 